\title{
Estimation of Molecular Weight in Terms of the Gel Effect in Radical Polymerization
}

\author{
Katsukiyo ITO \\ Government Industrial Research Institute, Nagoya, \\ Hiratemachi 1-chome, Kita-ku, Nagoya 462, Japan.
}

(Received February 29, 1980)

\begin{abstract}
In consideration of the modern idea of reptation, it is proposed that the rate of termination is proportional to $n^{-1 / 2}$ ( $n=$ chain length) when $n$ is less than a critical chain length $n_{\mathrm{c}}$, but the rate is proportional to $n^{-2}$ when $n>n_{\mathrm{c}}$. The molecular weight in terms of the gel effect is calculated by using such a rate. This molecular weight fits sufficiently to the experimental molecular weight obtained previously in a radical polymerization of methyl methacrylate. Further, the rate constant of termination between small polymer radicals is discussed by the free volume theory.

KEY WORDS Molecular Weight / Radical Polymerization / Gel Effect /

Reptation Model / Termination Rate / Methyl Methacrylate / Free Volume /
\end{abstract}

In studying the gel effect in radical polymerization, it was found that the termination rate between polymer radicals depends on their chain length, ${ }^{1-3}$ since the rate is translational diffusioncontrolled. Here, a typical equation, describing such dependence, is

$$
k_{\mathrm{t}, n s} \propto\left(n^{-a}+s^{-a}\right)
$$

where $k_{\mathrm{t}, n s}$ is the rate constant of termination between polymer radicals of chain length $n$ and $s$, and $a$ is the parameter set to be the same constant in the all range of chain length. Generally, the $n$ dependence of the coefficient of translational diffusion at $n>n_{\mathrm{c}}$ is markedly larger than that at $n \leqq n_{\mathrm{c}}$, where $n_{\mathrm{c}}$ is a critical chain length and has been estimated by the classical idea of polymer entanglement ${ }^{4-6}$ and the modern idea of reptation..$^{7-10}$ Thus, on the assumption that the rate is proportional to the coefficient of the translational diffusion, $a$ in eq 1 should not be the same constant for all chain length. Recently, in order to study the gel effect, certain methods based on the classical idea of entanglement have been proposed. ${ }^{11-14}$ The author has formulated the rate equation only when the transfer of polymer radical to solvent predominates, no equation could be formulated when such a transfer was not predominant, owing to the difficulty involved. In the other methods, ${ }^{12,13}$ the termination rate at $n \leqq n_{\mathrm{c}}$ was distincted from the termination rate at $n>n_{\mathrm{c}}$, because of the entanglement density. However, in spite of the $n$-dependence of the translational diffusion, ${ }^{4-10}$ this dependence was not considered. In this paper, eq 1 is modified by the modern idea of reptation. ${ }^{7-10}$ The molecular weight of a polymer is estimated by this modified equation.

\section{THEORY}

The termination rate equation is rewritten as ${ }^{1,2}$

$$
k_{\mathrm{t}, n s}=4 \pi R D
$$

where $R$ is reaction radius between the end radicals of the polymers and $D$ is the relative diffusion coefficient explained below. When $n \leqq n_{\mathrm{c}}$, Einstein and Stokes' relation, given by eq 3 , may be adopted for evaluating the diffusion of the polymers. ${ }^{1,2}$

$$
D=D_{0}\left(n^{-1 / 2}+s^{-1 / 2}\right)
$$

where $D_{0}$ is the diffusion coefficient of monomer unit. When $n>n_{\mathrm{c}}$ reptation $^{7-10}$ shows that the diffusion coefficient of the polymer is proportional to $n^{-2}$. Thus, $D$ is given by

$$
D=D_{0} n_{\mathrm{c}}^{3 / 2}\left(n^{-2}+s^{-2}\right)
$$

Introducing eq 3 and 4 into eq 2 , eq 1 is rewritten as

$$
\begin{gathered}
k_{\mathrm{t}, n s}=k\left(\zeta_{n}+\zeta_{s}\right) \\
\left(\zeta=n^{-1 / 2} \text { at } n, s \leqq n_{\mathrm{c}} ; \zeta=n_{\mathrm{c}}{ }^{3 / 2} n^{-2} \text { at } n, s>n_{\mathrm{c}}\right)
\end{gathered}
$$


where $k=4 \pi R D_{0}$, and $n_{\mathrm{c}}$ is evaluated by

$$
n_{\mathrm{c}}=\frac{\left(18 \pi^{2}\right)^{1 / 2}}{A} c^{-1.25}
$$

where $c$ is the polymer concentration and $A$ is a constant depending on size of the monomer. ${ }^{9}$

The rate equation for radical polymerization is

$$
\begin{aligned}
\frac{\mathrm{d}\left[\mathrm{N}_{n}\right]}{\mathrm{d} t}= & k_{\mathrm{p}}\left[N_{n-1}\right][\mathrm{M}]-k_{\mathrm{p}}\left[\mathrm{N}_{n}\right][\mathrm{M}] \\
& -\sum_{s=1}^{\infty} k_{\mathrm{t}, n s}\left[\mathrm{~N}_{n}\right]\left[\mathrm{N}_{s}\right]-k_{\mathrm{tr}}[\mathrm{S}]\left[\mathrm{N}_{n}\right]=0
\end{aligned}
$$

where $k_{\mathrm{p}}$ and $k_{\mathrm{tr}}$ are the rate constants of propagation and transfer, respectively; [M], [S], and $\left[\mathrm{N}_{n}\right]$ are the concentrations of monomer, solvent, and polymer radical with $n$, respectively. Using the same method as in previous papers, ${ }^{15,16}$ the equation for the fraction of polymer radicals with $n$ was determined as

$$
\begin{gathered}
\frac{\left[\mathrm{N}_{n}\right]}{[\mathrm{N}]}=\frac{F(n)}{F(1)+F(2)+\cdots+F(\infty)} \\
F(n)=\frac{1}{g(1)} \cdot \frac{1}{g(2)} \cdots \cdots \frac{1}{g(n)} \\
g(n)=1+C_{\mathrm{tr}}+\frac{f k_{\mathrm{d}}[\mathrm{C}]}{R_{\mathrm{p}}}(1+\zeta / \bar{k}) \\
\bar{k}=\sum_{s=1}^{n_{\mathrm{c}}} s^{-1 / 2} \frac{\left[\mathrm{N}_{s}\right]}{[\mathrm{N}]}+n_{\mathrm{c}}^{3 / 2} \sum_{s=n_{\mathrm{c}}+1}^{\infty} s^{-2} \frac{\left[\mathrm{N}_{s}\right]}{[\mathrm{N}]} \\
\left([\mathrm{N}]=\sum_{s=1}^{\infty}\left[\mathrm{N}_{s}\right]\right)
\end{gathered}
$$

where $C_{\mathrm{tr}}=k_{\mathrm{tr}}[\mathrm{S}] / k_{\mathrm{p}}[\mathrm{M}], f$ is the fraction of a primary radical escaping from solvent cage, $k_{\mathrm{d}}$ is the decomposition rate constant of the initiator, [C] is the initiator concentration, and $R_{\mathrm{p}}$ is the polymerization rate. To estimate the $\bar{k}$-value, eq $8-11$ is solved numerically. That is, an appropriate $\bar{k}$-value is set up. The computation based on eq $8-11$ yields a more probable value. Repeating such computation causes $\bar{k}$ to converge the most probable value. By using this value, the most probable $\left[\mathrm{N}_{n}\right] /[\mathrm{N}]$ can be calculated.

When disproportionation predominates, the production rate of the non-reacting polymer with $n$ is

$$
R_{\mathrm{t}, n}=\sum_{s=1}^{\infty} k_{\mathrm{t}, n s}\left[\mathrm{~N}_{n}\right]\left[\mathrm{N}_{s}\right]+k_{\mathrm{tr}}[\mathrm{S}]\left[\mathrm{N}_{n}\right]
$$

$$
=f k_{\mathrm{d}}[\mathrm{C}]\left(1+\frac{\zeta}{\bar{k}}+\frac{C_{\mathrm{tr}} R_{\mathrm{p}}}{f k_{\mathrm{d}}[\mathrm{C}]}\right) \frac{\left[\mathrm{N}_{n}\right]}{[\mathrm{N}]}
$$

Thus, the instantaneous fraction $\phi(n)$ of a nonreacting polymer with $n$ becomes

$$
\begin{aligned}
\phi(n)= & \frac{R_{\mathrm{tn}}}{\sum_{n=1}^{\infty} R_{\mathrm{tn}}} \\
& =\left(\frac{1+\zeta / \bar{k}+R_{\mathrm{p}} C_{\mathrm{tr}} / f k_{\mathrm{d}}[\mathrm{C}]}{2+R_{\mathrm{p}} C_{\mathrm{tr}} / f k_{\mathrm{d}}[\mathrm{C}]}\right) \frac{\left[\mathrm{N}_{n}\right]}{[\mathrm{N}]}
\end{aligned}
$$

By using $\phi(n)$, the instantaneous number-average degree of polymerization $\bar{p}_{n}$ and the instantaneous weight-average one $\bar{p}_{w}$ can be described as

$$
\begin{gathered}
\bar{p}=\sum_{n=1}^{\infty} n \phi(n) \\
\bar{p}_{w}=\frac{\sum n^{2} \phi(n)}{\sum n \phi(n)}
\end{gathered}
$$

The integrated number-average degree of polymerization $\bar{P}_{n}$ and the integrated weight-average one $\bar{P}_{w}$ at conversion $x$ are ${ }^{12,17-19}$

$$
\begin{gathered}
\bar{P}_{n}=\frac{x}{\int_{0}^{x} \mathrm{~d} x / \bar{p}_{n}} \\
\bar{P}_{w}=\frac{1}{x} \int_{0}^{x} \bar{p}_{w} \mathrm{~d} x
\end{gathered}
$$

\section{DISCUSSION}

\section{Molecular Weight}

Balke and Hamielec ${ }^{19}$ obtained extensive data for finding the relationship among molecular weight, conversion, and time in the polymerization of methyl methacrylate (MMA) initiated by 2,2'azobisisobutyronitrile (AIBN). They estimated the theoretical molecular weight by the convensional equation, assuming that the termination rate is independent of the chain length. In spite of the extensive modification of this equation, the calculated weight-average degree of polymerization deviated from the experimental data. In the present paper, it is shown that the rate equations described 
in the preceeding section fit sufficiently to the Balke and Hamielec data.

In the termination between poly(methyl methacrylate) (PMMA) radicals, disproportionation predominates. ${ }^{19,20}$ Thus, eq 12 is adopted without any modification for coupling. $\left[N_{n}\right] /[\mathrm{N}]$ can be calculated when $f k_{\mathrm{d}}[\mathrm{C}] / R_{\mathrm{p}}, \quad n_{\mathrm{c}}, \quad$ and $C_{\mathrm{tr}}$ are known. $f k_{\mathrm{d}}[\mathrm{C}] / R_{\mathrm{p}}\left([\mathrm{C}]=[\mathrm{C}]_{0} \exp \left(-k_{\mathrm{d}} t\right)\right.$ where $[\mathrm{C}]_{0}$ is the initial concentration of initiator and $t$ is time) is estimated from the Balke and Hamielec data (Table I to III). Here, the decomposition rate is estimated by $^{21}$

$$
k_{\mathrm{d}}=1.58 \times 10^{15} \exp (-15500 / T) \quad s^{-1}
$$

where $T$ is the absolute temperature. Berry and Fox ${ }^{22}$ estimated a critical chain length as 300 from rheological experiments with undiluted PMMA $(c=1)$. Brooks ${ }^{14}$ used this value for explaining the data of the polymerization rate of MMA. In the present paper, the critical chain length is also estimated by using 300 . That is, by setting $n_{\mathrm{c}}=300$ at $c=1$, eq 6 becomes

$$
n_{\mathrm{c}}=300 c^{-1.25}
$$

Table I. The calculated instantaneous degree of polymerization from the experimental data ${ }^{19}$ in the polymerization of MMA at

\begin{tabular}{|c|c|c|c|c|c|}
\hline$x$ & $10^{5} f k_{\mathrm{d}} / R_{\mathrm{p}}$ & $1000 \bar{k}$ & $\bar{p}_{n}$ & $\bar{p}_{w}$ & $10^{-7} k$ \\
\hline 0 & 15.0 & 28.57 & $\begin{array}{l}3223 \\
3218^{\mathrm{d}} \\
3218^{\mathrm{b}}\end{array}$ & $\begin{array}{l}8774 \\
6435^{\mathrm{d}} \\
7191^{\mathrm{b}}\end{array}$ & \\
\hline 0.15 & 13.97 & 26.02 & $\begin{array}{l}3460 \\
3458^{\mathrm{c}} \\
3446^{\mathrm{d}}\end{array}$ & $\begin{array}{l}9877 \\
9399^{\mathrm{c}} \\
6892^{\mathrm{d}}\end{array}$ & \\
\hline 0.2 & 10.26 & 18.70 & $\begin{array}{l}4695 \\
4687^{\circ} \\
4630^{d}\end{array}$ & $\begin{array}{r}15368 \\
12653^{\mathrm{c}} \\
9259^{\mathrm{d}}\end{array}$ & 43.3 \\
\hline 0.25 & 6.86 & 12.64 & $\begin{array}{l}6944 \\
6914^{\mathrm{c}} \\
6758^{\mathrm{d}}\end{array}$ & $\begin{array}{l}22910 \\
18024^{\mathrm{c}} \\
13513^{\mathrm{d}}\end{array}$ & 25.6 \\
\hline 0.3 & 5.42 & 9.578 & $\begin{array}{l}8649 \\
8615^{\mathrm{c}} \\
8389^{\mathrm{d}}\end{array}$ & $\begin{array}{l}28985 \\
22389^{\mathrm{c}} \\
16779^{\mathrm{d}}\end{array}$ & 18.66 \\
\hline 0.35 & 3.75 & 6.642 & $\begin{array}{l}11739 \\
11579^{\mathrm{c}} \\
11655^{\mathrm{d}}\end{array}$ & $\begin{array}{l}41410 \\
31850^{\mathrm{c}} \\
23310^{\mathrm{d}}\end{array}$ & 11.25 \\
\hline 0.4 & 2.526 & 4.502 & $\begin{array}{l}16301 \\
16369^{\mathrm{c}} \\
16308^{\mathrm{d}}\end{array}$ & $\begin{array}{l}54371 \\
42243^{\mathrm{c}} \\
32615^{\mathrm{d}}\end{array}$ & 6.53 \\
\hline 0.45 & 1.954 & 3.642 & & & 4.12 \\
\hline 0.5 & 1.012 & 2.107 & & & 1.602 \\
\hline 0.55 & 0.855 & 1.766 & & & 1.120 \\
\hline 0.6 & 0.866 & 1.735 & & & 0.940 \\
\hline
\end{tabular}
$50^{\circ} \mathrm{C}$ in the presence of $[\mathrm{AIBN}]=0.5 \% \mathrm{a}$

${ }^{a} k_{\mathrm{d}}=0.00000233 \mathrm{~s}^{-1}, C_{\mathrm{trm}}=0.0000108, k_{\mathrm{p}}=559 \mathrm{dm}^{3} \mathrm{~mol}^{-1} \mathrm{~s}^{-1}$.

${ }^{b}$ Obtained by Appendix 1.

' Equation 16 when $a=1 / 2$.

${ }^{\mathrm{d}}$ Equation 16 when $a=0$. 
In previous papers, ${ }^{12,19}$ transfer to the monomer was neglected. However, this transfer is important at high conversion. The importance of this transfer is shown by comparing $f k_{\mathrm{d}}[\mathrm{C}] / R_{\mathrm{p}}$ and the transfer constant with the monomer $C_{\mathrm{trm}}$, as is also shown by eq 10. Here, $C_{\text {trm }}$ is estimated by ${ }^{23}$

$$
\log _{10} C_{\mathrm{trm}}=-1.13-\frac{1240}{T}
$$

As is shown in Table I to II, $C_{\text {trm }}$ is comparable to $f k_{\mathrm{d}}[\mathrm{C}] / R_{\mathrm{p}}$ at high conversion; thus, the transfer to the monomer cannot be neglected. It is recognized that the transfer to AIBN is negligible. ${ }^{24-27}$ Also, the concentration of AIBN is not comparable with that of MMA in the present polymerization. Thus, the transfer to AIBN is neglected in the present calculation.

The values calculated are shown in Table I to III. At low conversion, the instantaneous molecular weight is equal to the integrated molecular weight which is expected to be the experimental molecular weight. However, even though the calculated number-average degree of polymerization is in a good agreement with the experimental degree of polymerization, the calculated weight-average de- gree of polymerization deviated from the experimental degree of polymerization $\left(p_{w}=7195\right.$ at $x=0.0801$ at $50^{\circ} \mathrm{C}$ and 2680 at $x=0.04$ at $70^{\circ} \mathrm{C}$ in the presence of $[\mathrm{AIBN}]=0.5 \%$ ). This may be caused by the fact that the $n$-dependence of the termination rate is $n^{-1 / 2}$ for the whole range of chain length, because $n_{\mathrm{c}}$ becomes infinite. However, at a conversion so low that $x \rightarrow 0$, the $n$-dependence of the rate is less than $n^{-1 / 2}$ when $n>100 .{ }^{15,16,28-30}$ Thus, the average degree of polymerization is calculated by the author's method ${ }^{15}$ (Appendix 1 and Table I to III). Certainly, the method in Appendix 1 is better than that based on eq 5 , since the values obtained in Appendix fit the experimental data. At about $x \simeq 0.1$, a correct calculation of molecular weight is very difficult, since the relationship between the expansion of the polymer coil, and conversion is very complex, ${ }^{31}$ and the lower limit of conversion, to which eq 5 is applicable is not fully known. The aim of the present paper is not to set forth the kinetics at low conversion, but at a conversion high enough so that the gel effect becomes important. Consequently, more detailed research has not been carried out, and $\bar{p}_{w}$ has been designated as the experimental value of $7200\left(x=0\right.$ to 0.1 at $\left.50^{\circ} \mathrm{C}\right)$,

Table II. The calculated instantaneous degree of polymerization from the experimental data ${ }^{19}$ in the polymerization of MMA at $70^{\circ} \mathrm{C}$ in the presence of $[\mathrm{AIBN}]=0.5 \% \mathrm{o}$

\begin{tabular}{lccccc}
\hline \multicolumn{1}{c}{$10^{4} f k_{\mathrm{d}}[\mathrm{C}] / R_{\mathrm{p}}$} & $1000 \bar{k}$ & $\bar{p}_{n}$ & $\bar{p}_{w}$ & $10^{-7} k$ \\
\hline 0 & 4.35 & 47.76 & 1127 & 3051 \\
& & & $1127^{\mathrm{b}}$ & $2689^{\mathrm{b}}$ & \\
0.2 & 4.33 & 46.90 & 1137 & 3222 & 45.0 \\
0.25 & 3.20 & 38.10 & 1529 & 4606 & 27.4 \\
0.3 & 2.34 & 29.74 & 2092 & 6615 & 17.45 \\
0.35 & 1.797 & 23.19 & 2702 & 8767 & 11.21 \\
0.4 & 1.342 & 17.44 & 3526 & 121.01 & 7.23 \\
0.45 & 1.016 & 13.30 & 4609 & 15875 & 4.66 \\
0.5 & 0.839 & 10.76 & 5540 & 18640 & 3.22 \\
0.55 & 0.682 & 6.632 & 6661 & 30130 & 2.25 \\
0.6 & 0.475 & 5.128 & 9185 & 33892 & 1.239 \\
0.65 & 0.402 & 4.921 & 10466 & 33954 & 0.821 \\
0.7 & 0.408 & 4.175 & 11456 & 0.662 \\
0.75 & 0.345 & 3.995 & 11441 & 39285 & 0.394 \\
0.8 & 0.35 & 11.42 & 3437 & 12459 & 0.276
\end{tabular}

a $k_{\mathrm{d}}=0.0000382 \mathrm{~s}^{-1}, C_{\mathrm{trm}}=0.0000181, k_{\mathrm{p}}=830 \mathrm{dm}^{3} \mathrm{~mol}^{-1} \mathrm{~s}^{-1}$.

b Obtained by Appendix 1. 
Table III. The calculated instantaneous degree of polymerization from the experimental data ${ }^{19}$ in the polymerization of MMA at $90^{\circ} \mathrm{C}$ in the presence of $[\mathrm{AIBN}]=0.5 \% \mathrm{o}^{\mathrm{a}}$

\begin{tabular}{lccccc}
\hline \multicolumn{1}{c}{$10^{4} f k_{\mathrm{d}}[C] / R_{\mathrm{p}}$} & $1000 \bar{k}$ & $\bar{p}_{n}$ & $\bar{p}_{w}$ & $10^{-7} k$ \\
\hline 0 & 10.68 & 73.95 & 466 & 1256 & $1194^{\mathrm{b}}$ \\
& & & $464^{\mathrm{b}}$ & 1411 & 28.9 \\
0.2 & 0.51 & 69.96 & 522 & 1478 & 25.6 \\
0.25 & 9.18 & 68.54 & 541 & 2109 & 15.02 \\
0.3 & 6.68 & 57.44 & 736 & 2325 & 12.66 \\
0.35 & 6.23 & 54.10 & 787 & 3046 & 8.59 \\
0.4 & 4.96 & 45.25 & 983 & 5247 & 5.19 \\
0.45 & 3.67 & 36.18 & 1321 & 7567 & 3.11 \\
0.5 & 2.67 & 27.43 & 1793 & 8597 & 2.01 \\
0.55 & 2.095 & 18.79 & 2275 & 9290 & 1.473 \\
0.6 & 1.845 & 17.83 & 2563 & 9894 & 1.099 \\
0.65 & 1.71 & 15.56 & 2756 & 11300 & 0.830 \\
0.7 & 1.63 & 13.31 & 2856 & 15790 & 0.520 \\
0.75 & 1.413 & 9.382 & 46235 & 18936 & 0.221 \\
0.8 & 0.954 & 13.378 & 5796 & 9404 & \\
0.85 & 0.738 & 13.87 & 2722 & & \\
\hline
\end{tabular}

a $k_{\mathrm{d}}=0.000460 \mathrm{~s}^{-1}, C_{\mathrm{trm}}=0.0000286, k_{\mathrm{p}}=1180 \mathrm{dm}^{3} \mathrm{~mol}^{-1} \mathrm{~s}^{-1}$.

b Obtained by Appendix 1 .

$2700\left(0\right.$ to 0.15 at $\left.70^{\circ} \mathrm{C}\right)$, and $942\left(0\right.$ to 0.2 at $90^{\circ} \mathrm{C}$ ) in the presence of $[\mathrm{AIBN}]=0.5 \%$. The $\bar{p}_{n}$ is calculated by the present method for the whole range of conversion. Molecular weight may be calculated by eq 16 as well as by eq 5 and so the importance of the reptation model can thus be seen.

$$
k_{\mathrm{t}, n s}=k\left(n^{-a}+s^{-a}\right)
$$

where $a=0$ applies to conventional case ${ }^{19}$ and $a=1 / 2$ to the conventional diffusion-controlled reaction. It is suprising that the difference between the instantaneous number average derived from eq 5 and that from eq 16 can be scarcely detected, as is shown in Table I, and any calculated number average fits the experimental data. Thus, the importance of reptation and the $n$-dependence of the rate can not be discussed by the number average. The weight average determined by eq 16 when $a=0$ is least (Table I) and deviates completely from the experimental data at 50 and $70^{\circ} \mathrm{C}$ (Figures 1 and 2). The weight average calculated by eq 16 when $a=1 / 2$ is not the best fit for the data at $50^{\circ} \mathrm{C}$ (Figure 1) and at $70^{\circ} \mathrm{C}$ without the final stage of polymerization (Figure 2). The weight average determined by eq 5 is the best fit for the data at any temperature without the final stage (Figures 1 to 3 ). In conclusion, the weight average determined by the reptation fits sufficiently the experimental data. However, at the final stage, the weight average calculated by eq 5 at $70^{\circ} \mathrm{C}$ deviates slightly from the data, but the weight average calculated by eq 5 at $90^{\circ} \mathrm{C}$ deviates considerably. The deviation at $90^{\circ} \mathrm{C}$ cannot be neglected, and so is discussed later.

\section{Termination Rate}

The average of the termination rate is

$$
\begin{aligned}
\overline{k_{\mathrm{t}}} & =\sum_{n=1}^{\infty} \sum_{s=1}^{\infty} k_{\mathrm{t}, n s} \frac{\left[\mathrm{N}_{n}\right]}{[\mathrm{N}]} \frac{\left[\mathrm{N}_{s}\right]}{[\mathrm{N}]} \\
& =2 k \bar{k}
\end{aligned}
$$

Introduction of eq 17 into the conventional rate equation yields

$$
k=\left(\frac{f k_{\mathrm{d}}[\mathrm{C}]}{R_{\mathrm{p}}}\right)\left(\frac{[\mathrm{M}]^{2}}{\bar{k} R_{\mathrm{p}}}\right) k_{\mathrm{p}}{ }^{2}
$$

$k$ can be estimated by using the values in Tables I to III and the propagation rate as ${ }^{30}$

$$
k_{\mathrm{p}}=4.92 \times 10^{5} \exp (-2192 / T) \quad \mathrm{dm}^{3} \mathrm{~mol}^{-1} \mathrm{~s}^{-1}
$$




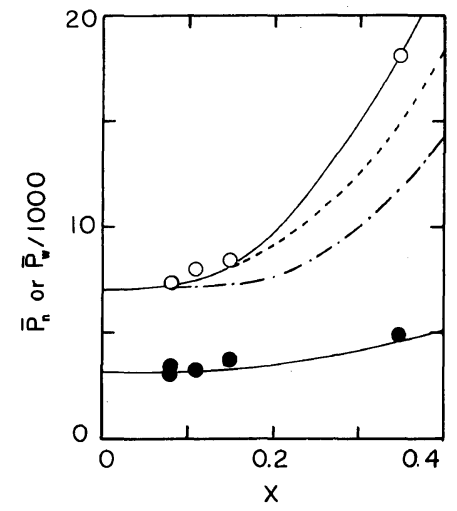

Figure 1. Estimation of the integrated molecular weight. Experimental data $\bar{P}_{n}(\bigcirc)$ and $\bar{P}_{w}(\bigcirc)$ in the polymerization of $\mathrm{MMA}$ at $50^{\circ} \mathrm{C}$ in the presence of $[\mathrm{AIBN}]=0.5 \%{ }^{19}(-)$, the degree of polymerization calculated by eq $5 ;(---)$, the degree of polymerization calculated by eq 16 when $a=1 / 2 ;(-\cdot-)$, the degree of polymerization calculated by eq 16 when $a=0$.

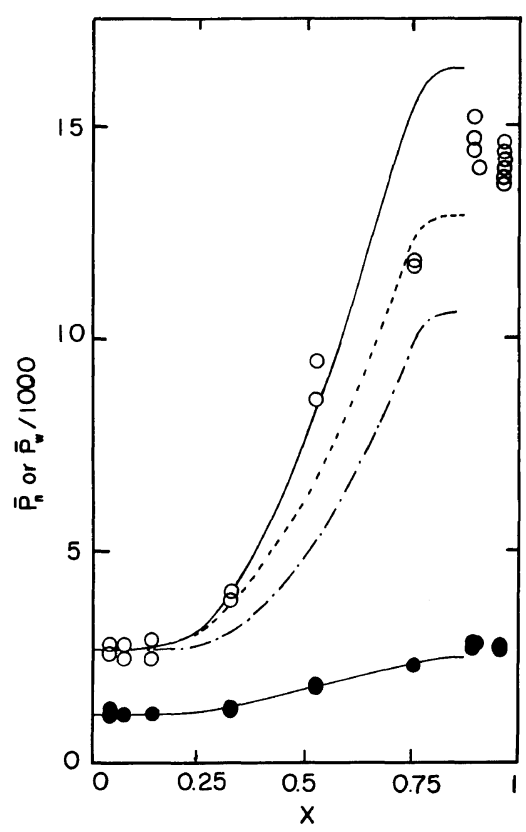

Figure 2. Estimation of the integrated molecular weight for the experimental data ${ }^{19}$ in the polymerization of MMA at $70^{\circ} \mathrm{C}$ in the presence of $[\mathrm{AIBN}]=0.5 \%$. The same symbols in Figure 1.

The $2 k$-value obtained (Table I to III) is in $10^{9}$ to $10^{8}$ $\mathrm{dm}^{3} \mathrm{~mol}^{-1} \mathrm{~s}^{-1}$ at $x \simeq 0.2$ and this is reasonable,

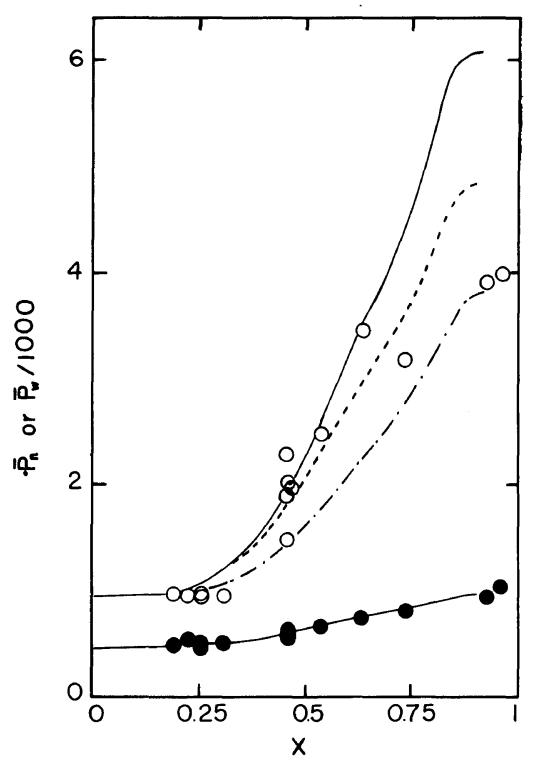

Figure 3. Estimation of the integrated molecular weight for the experimental data ${ }^{19}$ in the polymerization of MMA at $90^{\circ} \mathrm{C}$ in the presence of $[\mathrm{AIBN}]=0.5 \%$. The same symbols in Figure 1.

because of the good agreement with the rate constant of the diffusion-controlled reaction between small reactants. ${ }^{32,33}$ With an increase in the polymer concentration, $k$ decreases. Such a decrease may be studied by the free volume theory. ${ }^{3,34}$ That is, $k$ at the free volume may be given by

$$
\ln k=\text { const }-\frac{\gamma^{*} v^{*}}{V_{\mathrm{f}}}
$$

where $\gamma^{*}$ is an overlap factor and $v^{*}$ is the critical free volume sufficient to permit a segment to jump in the place where another segment displaces. $V_{\mathrm{f}}$ is estimated by Kelley and Buche's equation. ${ }^{35,36}$

$$
\begin{aligned}
V_{\mathrm{f}}= & \left\{\left[25+0.48\left(T-T_{\mathrm{qp}}\right)\right] c\right. \\
& \left.+\left[25+\left(T-T_{\mathrm{gm}}\right)\right](1-c)\right\} / 1000
\end{aligned}
$$

where $T_{\mathrm{gp}}$ and $T_{\mathrm{gm}}$ are the glass-transition temperatures of the polymer and monomer, respectively. As is shown in Figure 4 the relationship between $\ln k$ and $1 / V_{\mathrm{f}}$ when $x<0.5$ would be the line with a slope of $\gamma^{*} i^{*} \simeq 1.0$ at any temperature. However, when $x>0.5$, the experimental data deviate from eq 19 .

The reason for the experimental-data deviation 


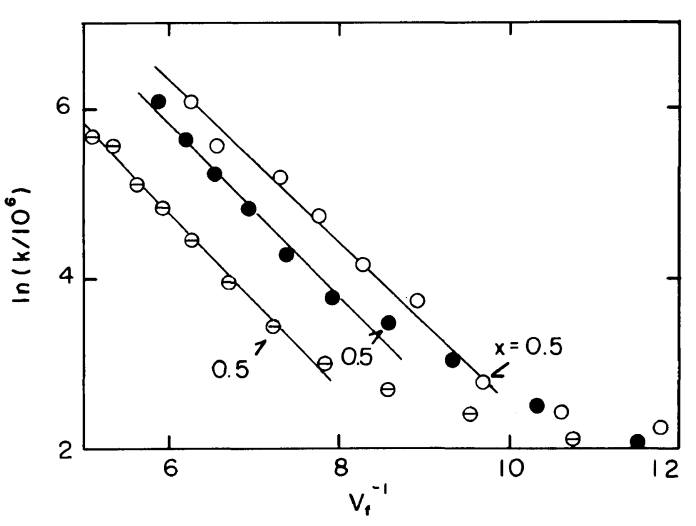

Figure 4. Relationship between $k$ and the free volume at $50(\bigcirc), 70(\bigcirc)$, and $90(\ominus)^{\circ} \mathrm{C}$.

from eq 19 is: (1) $f$ might decrease with the promotion of polymerization above 0.5 . In the past, it was not shown that $f$ is not variable when $x>0.5 .{ }^{14,37}(2) k_{\mathrm{p}}$ might decrease with an increase in $x .^{38}$ (3) The displacement of radical position on the polymer chain moves not only by translational diffusion, but also by propagation. That is, when the radical adds one-monomer unit $\left(\mathrm{N}_{n}+\mathrm{M} \rightarrow \mathrm{N}_{n+1}\right)$, the radical position moves a distance $l$ which is twice the carbon-carbon bond length. Such a movement is independent of the translational diffusion. The number of monomer units added is $k_{\mathrm{p}}[\mathrm{M}][\mathrm{N}] /[\mathrm{N}]=k_{\mathrm{p}}[\mathrm{M}] s^{-1} .^{2,39}$ Such an addition is also random. Therefore, following the diffusion theory of a particle, this movement may be evaluated by

$$
D_{\text {pro }}=\frac{l^{2}}{6} k_{\mathrm{p}}[\mathrm{M}] \quad \mathrm{cm}^{2} \mathrm{~s}^{-1}
$$

The extent of $D_{\text {pro }}$ is estimated to be $10^{-12} \sim 10^{-13}$ $\mathrm{cm}^{2} \mathrm{~s}^{-1}$, since $l \simeq 3 \times 10^{-8} \mathrm{~cm}$ and $k_{\mathrm{p}}[\mathrm{M}] \simeq 1000$ $\mathrm{s}^{-1} \cdot{ }^{31,40}$ Perhaps, $D_{0}$ may be $10^{-6} \mathrm{~cm}^{2} \mathrm{~s}^{-1}$ at $x=0.2$. By expanding the line in Figure 4 in the range of $x>0.5$, the $D_{0}$ at the final stage is estimated to be $10^{-9} \mathrm{~cm}^{2} \mathrm{~s}^{-1}$. Now, we consider a polymer radical with $n=60000$, which is a typical size, as is shown in Appendix 2. Its diffusion coefficient is $10^{-9} \times(300 / 60000)^{2}=2.5 \times 10^{-14} \mathrm{~cm}^{2} \mathrm{~s}^{-1}$ which is less than $D_{\text {pro. }}$. That is, at the final stage, the displacement of the radical position by $D_{\text {pro }}$ may not be neglected. When the above problems are cleared up, the deviation of the experimental data from eq 19 may be explained. Further, the displacement of the radical position by the propagation may be important for explaining why the calculated $\bar{P}_{w}$, using eq 5 , deviates from the experimental $\bar{P}_{w}$ at $90^{\circ} \mathrm{C}$ at the final stage. That is, $D_{\text {pro }}$ is larger at higher temperatures, because of larger $k_{\mathrm{p}}$, and the termination rate is larger than $(2 / 3) \pi l^{2} R k_{\mathrm{p}}[\mathrm{M}]$ even if $D \rightarrow 0$. The upper limit of the polymer size may be controlled by the rate, as $(2 / 3) \pi l^{2} R k_{\mathrm{p}}[\mathrm{M}]$, and is less than the limit calculated by using eq 5 . Thus, it may be expected that the calculated $\bar{P}_{w}$ using $k_{\mathrm{t}, n s}=4 \pi R\left(D+D_{\mathrm{pro}}\right)$ fits the experimental data.

\section{APPENDIX}

1. At very low conversion, the term $\xi / \bar{k}$ in eq 10 , 12 , and 13 is rewritten as

$$
\left[\left(k_{1} n^{-e_{1}}+k_{2} n^{-e_{2}}+\rho k_{3} n^{-e_{3}}\right) /\left(k_{1} \bar{k}+k_{2} \bar{k}_{2}+\rho k_{3} \bar{k}_{3}\right)\right],
$$

with the notation in ref 15 . The molecular weight in the table is calculated accordingly, with the same parameters for $k_{j}, e_{j}(j=1$ to 3$)$, and $\rho$ in ref 15 .

2. Because of the $n$-dependence of $k_{\mathrm{t}, n s}$, the number-average degree of polymerization of the radical is not equal to that of the non-reacting polymer, but $\bar{n}=\sum n\left[\mathrm{~N}_{n}\right] /[\mathrm{N}]$. When $x=0.5$ at $50^{\circ} \mathrm{C}$, $\bar{n}=54600$. Thus, $\bar{n}=60000$ is a typical size when $x>0.5$.

\section{REFERENCES}

1. S. W. Benson and A. M. North, J. Am. Chem. Soc., 84, 935 (1962).

2. K. Ito, J. Polym. Sci., A-2, 7, 241 (1969).

3. K. Ito, J. Polym. Sci., Polym. Chem. Ed., 13, 401 (1975).

4. F. Bueche, J. Chem. Phys., 20, 1959 (1952).

5. F. Bueche, J. Appl. Phys., 26, 738 (1955).

6. W. W. Graessley, J. Chem. Phys., 43. 2696 (1965).

7. P. G. Gennes, J. Chem. Phys., 55, 572 (1971).

8. M. Doi and S. F. Edwards, J. Chem. Soc., Faraday Trans. 2, 74, 560, 918, 1789, 1802 (1978), and 75, 38 (1979).

9. J. Klein, Macromolecules, 11, 852 (1978).

10. J. Klein, Nature (London), 271, 143 (1978).

11. K. Ito, J. Polym. Sci., Polym. Chem. Ed., 13, 1297 (1975).

12. J. N. Cardenas and K. F. O'Driscoll, J. Polym. Sci., Polym. Chem. Ed., 14, 883 (1976).

13. K. Arai and S. Saito, J. Chem. Eng. Jpn., 9, 302 (1976).

14. B. W. Brooks, Proc. R. Soc. London, Ser. A, 357, 183 (1977) 
15. K. Ito, Polym. J., 11, 795 (1979).

16. K. Ito, J. Polym. Sci., Polym. Chem. Ed., 18, 701 (1980).

17. A. W. Hui and A. E. Hamielec, J. Polym. Sci., C, 25, 167 (1968).

18. T. Imoto, "Kobunshi no Seizo (Production of Polymers)," Nikkan Kogyo Shinbun, Tokyo, 1974.

19. S. T. Balke and A. E. Hamielec, J. Appl. Polym. Sci., 17, 905 (1973).

20. G. Bonta, B. M. Gallo, S. Russo, and C. Uliana, Polymer, 17, 217 (1976).

21. J. Van Hook and A. Tobolsky, J. Am. Chem. Soc., 80, 779 (1958).

22. G. C. Berry and T. G Fox, Adv. Polym. Sci., 5, 261 (1967).

23. N. Stickler and G. Meyerhoff, Makromol. Chem., 179, 2729 (1978).

24. B. Baysal and A. V. Tobolsky, J. Polym. Sci., 8, 529 (1952).

25. S. R. Palit, U. S. Nadi, and N. C. Saha, J. Polym. Sci., 14, 295 (1954).

26. N. C. Saha, U. S. Nadi, and S. R. Palit, J. Chem. Soc., 1 (1958).

27. G. V. Schulz, G. Henrici, and S. Olivé, $Z$. Elektrochem., 60, 296 (1956).
28. K. Ito, J. Polym. Sci., Polym. Chem. Ed., 12, 1991 and 2581 (1974); 13, 521 (1975); 14, 1761 (1976).

29. K. Horie, I. Mita, and H. Kambe, Polym. J., 4, 341 (1973).

30. H. K. Mahabadi and K. F. O'Driscoll, J. Macromol. Sci., Chem., A11, 967 (1977).

31. H. Yamakawa, J. Chem. Phys., 34, 1360 (1961).

32. G. V. Schulz, Z. Phys. Chem. Neue Folge, 8, 284 (1957).

33. U. B. Borgwardt, W. Schnabel, and A. Henglein, Makromol. Chem., 164, 176 (1969).

34. K. Ito, J. Polym. Sci., A-1, 7, 2995 (1969); 8, 1313 and 1823 (1970).

35. F. N. Kelley and F. Bueche, J. Polym. Sci., 50, 549 (1961).

36. K. Horie, I. Mita, and H. Kambe, J. Polym. Sci., A1, 6, 2663 (1968).

37. H. K. Mahabadi and G. Meyerhoff, Eur. Polym. J., 15, 607 (1979).

38. P. Heyden and H. Melville, J. Polym. Sci., 43, 201 (1960).

39. K. Ito, J. Polym. Sci., A-1, 7, 827 (1969).

40. P. J. Flory, "Principles of Polymer Chemistry," Cornell University Press, Ithaca, N.Y., 1953. 